\title{
Prehospital vs. emergency department pronouncement of death: a cost analysis
}

\author{
Mathew Cheung, MD;* Laurie Morrison, MD, MSc; † P. Richard Verbeek, MD†
}

\begin{abstract}
Objectives: National survival rates for out-of-hospital cardiac arrests are less than $5 \%$, and substantial resources are associated with transporting cardiac arrest victims to hospital for emergency department (ED) resuscitation. The low overall survival rate and the identification of predictors of unsuccessful resuscitation have opened debate on the "futility" of transporting such patients to the ED. This study compares the costs of prehospital pronouncement of death to the costs of transporting patients to a hospital ED for physician pronouncement.

Methods: The study was a retrospective chart review on a matched cohort of out-of-hospital cardiac arrest patients. Patients were included if documentation was adequate and ambulance response time was less than 8 minutes. A cohort of 20 patients pronounced dead in the field were matched to 20 patients pronounced dead in an ED. Cases were matched on 6 evidence-based predictors of unsuccessful resuscitation. Direct medical costs and mean physician and prehospital provider times were compared.

Results: The total cost of pronouncement of death in the ED was $\$ 45.35$ higher than the cost of field pronouncement $(p<0.001)$. Paramedics spent more time delivering care when death was pronounced in the field ( 83.3 vs. $55.9 \mathrm{~min} ; p<0.001)$. Base hospital physicians spent more time when patients were transported to hospital for ED pronouncement (16.3 vs. $4.3 \mathrm{~min} ; p<0.001)$. Total provider time for field pronouncement was $15.5 \mathrm{~min}$ longer $(p=0.004)$, but field pronouncement consumed 12.0 min less physician time.

Conclusions: Paramedic pronouncement of death in the field is less costly than transporting patients to hospital for physician pronouncement. Pronouncement in the field requires more paramedic time but less physician time.

\section{RÉSUMÉ}

Objectifs : Les taux de survie à l'échelle nationale chez les victimes d'arrêt cardiaque à l'extérieur de l'hôpital sont inférieurs à $5 \%$ et des ressources substantielles sont allouées au transport de ces victimes vers l'hôpital pour une réanimation à l'urgence. Le faible taux de survie et l'identification de valeurs précvisionnelles de l'échec de la réanimation ont ouvert le débat sur la "futilité» du transport de ces patients vers l'urgence. La présente étude compare les coûts de la constatation du décès sur les lieux de l'incident aux coûts du transport du patient vers l'urgence pour la constatation du décès par le médecin à l'hôpital.

Méthodes: Il s'agit d'une revue rétrospective de dossiers d'une cohorte appariée de victimes d'arrêt cardiaque en situation pré-hospitalière. Les patients étaient inclus dans l'étude si la documentation était adéquate et que le délai de réponse de l'ambulance était de moins de 8 minutes. Une cohorte de 20 patients prononcés morts sur les lieux de l'incident fut appariée à 20 patients
\end{abstract}

\footnotetext{
*University of Toronto, Toronto, Ont.; †Division of Prehospital Care, Department of Emergency Services, Sunnybrook and Women's College Health Sciences Centre, Toronto, and Division of Emergency Medicine, Department of Medicine, University of Toronto, and Toronto Ambulance Services, Toronto

Received: Oct. 29, 1999; final submission: Sept. 21, 2000; accepted: Oct. 1, 2000

This article has been peer reviewed.
} 
prononcés morts à l'urgence. Les cas furent appariés à partir de 6 valeurs prévisionnelles fondées sur les données probantes de l'échec de la réanimation. Les coûts médicaux directs liés aux délais moyens d'administration des soins par le médecin et par les techniciens médicaux d'urgence furent comparés.

Résultats : Le coût total de la constatation du décès à l'urgence s'élevait à 45,35 \$ de plus que le coût de la constatation sur les lieux de l'incident $(p<0,001)$. Les techniciens médicaux d'urgence passèrent plus de temps à l'administration des soins lorsque le décès était constaté sur les lieux de I'incident $(83,3$ vs 55,9 min; $p<0,001)$. Les médecins à I'hôpital passèrent plus de temps à l'administration des soins lorsque les patients étaient transportés à l'hôpital pour la constatation du décès à l'urgence (16,3 vs 4,3 min; $p<0,001)$. Le délai total pour la constatation du décès sur les lieux de l'incident représentait 15,5 minutes de plus $(p=0,004)$, mais se traduisait par une économie de temps de 12 minutes pour le médecin.

Conclusions : La constatation du décès par les techniciens médicaux d'urgence sur les lieux de l'incident est moins coûteuse que de transporter le patient vers l'hôpital pour la constatation du décès par un médecin. La constatation du décès sur les lieux de l'incident demande plus de temps aux techniciens mais permet en revanche aux médecins de sauver du temps.

Key words: emergency medical services, death pronouncement, cost identification

\section{Introduction}

Over the past 30 years, Basic Life Support (BLS) and Advanced Life Support (ALS) paramedic programs have evolved to respond to potentially reversible cases of cardiac arrest. ${ }^{1,2}$ However, despite many refinements in the emergency medical services (EMS) system, survival rates from out-of-hospital cardiac arrest vary widely among communities and are estimated to be less than $5 \%$ nationally. ${ }^{3}$ Ontario's overall survival rate of $2.5 \%-3.9 \%$ is among the lowest in Canada. ${ }^{4,5}$

Recent studies have identified several predictors of unsuccessful prehospital resuscitation. ${ }^{4,6-15}$ Bonnin proposed that resuscitation efforts in primary cardiac arrest patients who are not in persistent ventricular fibrillation be terminated if there is no return of spontaneous circulation after 25 minutes of advanced cardiac life support (ACLS). ${ }^{6}$ Pepe and colleagues prospectively validated this finding, ${ }^{14}$ and others support on-line physician-guided field pronouncements by paramedics for such patients. ${ }^{16}$

The low likelihood of survival for certain out-of-hospital cardiac arrests, and the ability to identify indicators associated with death in the field has fostered debate on the "futility" of transporting patients with unsuccessful resuscitation to the emergency department (ED). ${ }^{11,17-19}$ Substantial risks and resources are associated with transporting such patients to the hospital. These include the diversion of ED staff from other patients, ${ }^{10}$ prolonged unavailability of prehospital care providers for other calls, the risk of ambulance collisions during rapid transport, ${ }^{16,17,20}$ and consumption of additional ED resources, with cost estimates ranging from US $\$ 2,000$ to $\$ 3,000$ per case. ${ }^{7,2}$
Some authors have examined the effectiveness of prehospital care in terms of mortality and patient outcomes, but little research has been done to estimate the costs of these programs. ${ }^{2,22-24}$ No studies have directly identified and compared the costs of pronouncing death in the field with the costs of transport to the ED for pronouncement. In Toronto, ALS (EMT-P) paramedics are permitted to pronounce death in the field under the guidance of a regional base hospital physician, while BLS (EMT-D) providers are obliged by law to resuscitate and transport all patients to the closest hospital. ${ }^{25}$ Thus, we conducted a retrospective chart review on a matched cohort of out-of-hospital cardiac arrest patients to identify and compare the costs of ALS pronouncement of death in the field to those of BLS assessment and transport for pronouncement in the ED. We hypothesized that field pronouncement would be associated with lower costs and less physician time in a population of patients who had similar predictors of poor survival.

\section{Methods}

\section{Setting}

The Toronto EMS system serves over 2.2 million people and receives 450,000 calls per annum. Firefighter first-responders trained in early defibrillation respond to all cardiac arrests. BLS paramedics work in pairs and deliver basic cardiopulmonary resuscitation and automatic defibrillation. ALS paramedics are trained in ACLS procedures, including defibrillation, intubation and drug administration for cardiac arrest. ALS availability is limited; thus, ALS providers care for only $50 \%$ of all cardiac arrest patients. BLS paramedics provide resuscitation when ALS crews are unavailable. 
A single base hospital, the Department of Emergency Services, Sunnybrook and Women's College Health Sciences Centre, oversees all medical procedures performed by paramedics in the region. However, only ALS paramedics are permitted to contact the base hospital emergency physician for instructions regarding patient management or pronouncement of death. Ontario legislation permits ALS and BLS crews to pronounce death only in the presence of rigor mortis, lividity, decomposition, or decapitation. $^{25}$

\section{Study eligibility}

A 2-year retrospective chart review (1994-1996) identified cardiac arrest patients who were transported by BLS paramedics (BLS-transport) and similar patients who were pronounced dead in the field by ALS paramedics after contact with base hospital physicians (ALS-pronounce). Cases were eligible for inclusion only if the ambulance response interval (vehicle dispatch to scene arrival) was less than 8 minutes, a common goal for optimizing out-of-hospital survival rates. ${ }^{26}$ To facilitate data collection and cost identification, the BLS cohort was limited to patients who were transported to the Sunnybrook base hospital. Cases were selected if ambulance call reports contained demographic data (age, sex, address), health information (medical history, advance directives if known), circumstances of resuscitation (witnessed or unwitnessed arrest, time to CPR, initial field rhythm, initial response to resuscitative efforts) and computer-documented dispatch times. Hospital records were also required for patients in the BLS-transport group.

\section{Exclusions}

Specific resuscitation situations rarely result in field pronouncements and often require rapid ALS transport to the ED. These situations made up the study's exclusion criteria, and included: pediatric arrests (patients under 18 years), traumatic arrests, suspected poisonings, hypothermia, persistent ventricular tachycardia or fibrillation, and patients in whom intubation was unsuccessful or impossible. Patients transported by ALS crews after field pronouncement in response to a family request were also excluded. The principal investigator (L.M.) confirmed adherence to inclusion and exclusion criteria during data abstraction.

\section{Case matching}

A MEDLINE search of English language peer-reviewed prehospital care research ${ }^{4,6-15}$ was undertaken to identify independent variables that predict unsuccessful resuscitation. Article bibliographies were reviewed to identify studies overlooked in the primary search. Subsequently, all 14 base hospital physicians were surveyed to confirm that the evidence-based predictors (Fig. 1) actually drive physician decisions regarding the aggressiveness of resuscitation and the appropriateness of pronouncement.

A standardized data abstraction form was used to extract predictor variable data from the ambulance call reports, and the predictors were used to match eligible BLS-transport patients to ALS-pronounce patients. Matching was conducted independently by 2 investigators (M.C. and L.M.) through a manual review and selection of appropriate matches for each of the first 20 BLS cases for whom a matching ALS case could be identified. This was followed by a consensus determination of the closest match for each case. Cases for which a match could not be found were excluded after the matching process.

\section{Cost analysis}

A cost identification analysis was performed to compare the 2 methods of pronouncement of death. Costs for each matched pair of cardiac arrest patients were determined in the following manner. BLS and ALS costs were calculated on a cost-per-unit-hour basis as described in a previous study by Nichol and colleagues. ${ }^{27}$ Variable EMS costs (vehicles, equipment, wages, benefits and education) were calculated at Can $\$ 111.60$ per unit hour for ALS providers and Can\$98.40 per unit hour for BLS providers. Direct physician cost for pronouncement of BLS-transport patients was based on actual Ministry of Health fees paid to base hospital physicians for each specific study patient. Ministry of Health funding for on-line medical direction was set at $\$ 62.40 / \mathrm{h}$. Because the same fixed EMS costs (i.e., costs of operating 911 emergency services, ambulance communication centres and ambulance bases) apply to both ALS and BLS providers, these were not included in the study. Institutional costs for ED care were unavailable because the

Fig. 1. Independent variables that predict unsuccessful resuscitation

- Age $( \pm 20 \text { years })^{4,6,9,15}$

- Time to CPR ( $<10$ minutes if witnessed; last seen $<60$ min or $\geq 60 \mathrm{~min}$, if unwitnessed $)^{4,6,7,9,15}$

- A do-not-resuscitate order, living will or substitute decision-maker who requests "no resuscitation" ${ }^{8}$

- Presence of a pre-existing terminal illness (e.g., cancer, end-stage renal or liver disease, AIDS) ${ }^{8}$

- Initial field rhythm (VF, asystole, pulseless electrical activity $)^{6,70-13,15}$

- Lack of response to initial therapy (i.e., no return of spontaneous circulation as defined by a spontaneous palpable pulse rate of 60 beats/min for at least one 5-minute period) $)^{7,14,27,28}$ 
hospital's financial database only collects data on admitted patients; therefore, the study underestimated ED care costs for BLS-transport patients. Costs were not adjusted for inflation or future increases. ${ }^{28}$

\section{Time analysis}

The same group of base hospital physicians supervised all pronouncements in the study, either by patch (ALS-pronounce) or in person (BLS-transport). Base hospital physician time involvement for ED pronouncement was determined from ED patient records and calculated as the interval between initial patient contact and time of pronouncement. Base hospital physician time involvement for field pronouncement was obtained from hospital-ALS patch records and represents the duration of telephone contact with ALS field paramedics. Duration of ALS and BLS paramedic involvement was obtained from the ambulance call report and calculated as the interval between call receipt and time of availability for return to active service after the call.

\section{Statistics}

A sample size of 20 pairs was determined as sufficient to test the null hypothesis that there is no difference in the total cost or physician time involvement between the 2 groups, assuming a matched-pair analysis with an $\alpha$ level of 0.05 and a $\beta$ level of 0.20 .The paired $t$-test was used to compare mean differences between the costs and times of pronouncement in the field vs. pronouncement in the ED. The significance level for comparisons was set $a$ priori at $p<$ 0.05. Statistical analysis was carried out using SAS (The SAS Institute, Cary, NC) and power/sample size calculation using Power and Precision. ${ }^{29}$ This study was approved by the Sunnybrook and Women's College Health Sciences Centre Research Ethics Board.

\section{Results}

During the study period, 456 cardiac arrest patients had a paramedic response time $<8$ minutes, underwent BLS resuscitation and transport, and had adequate ambulance call report documentation. Of these, 70 were pronounced dead in the Sunnybrook ED (BLS-transport cohort). Concurrently, ALS crews performed 168 field pronouncements on cardiac arrest patients with EMS response times $<8$ minutes and adequate ambulance call report documentation (ALS-pronounce cohort). From these 2 groups, 20 pairs of cardiac arrests were matched for all 6 matching parameters. Patient characteristics for the 2 study groups are shown in Table 1.

\section{Costs}

Figure 2 summarizes costs associated with the 2 methods of pronouncement. Paramedic costs were $\$ 63.33$ higher in the ALS-pronounce group ( $\$ 154.93$ vs. $\$ 91.60 ; p<0.001$ ), but physician costs were $\$ 108.69$ higher in the BLS-transport group ( $\$ 113.17$ vs. $\$ 4.47 ; p<0.001$ ). Therefore, total provider cost was $\$ 45.35$ less for ALS field pronouncement than for ED pronouncement of BLS-transported patients (\$159.41 vs. $\$ 204.76, p<0.001)$.

\section{Intervention time}

Figure 3 shows the mean duration of care and $95 \%$ confidence intervals for field and ED pronouncement according to provider. The mean duration of paramedic care was 27.5 minutes longer in the ALS-pronounce group (83.3 vs. 55.9 $\min ; p<0.001$ ), while base hospital physician time was 12.0 minutes longer in the BLS-transport group (16.3 vs. $4.3 \mathrm{~min} ; p<0.001$ ). Thus, the total (physician + paramedic) provider time was 15.5 minutes longer in the ALS-pronounce group than in the BLS-transport group (87.6 vs. $72.2 ; p=0.004)$.

\section{Discussion}

This study compared the resources associated with ALS field pronouncement and ED physician pronouncement among matched cardiac arrest patients unlikely to respond to further resuscitation. We found that BLS transport and ED physician pronouncement was associated with higher overall costs. ALS field pronouncement consumed a small-

\begin{tabular}{|c|c|c|}
\hline Matching variable & $\begin{array}{l}\text { BLS-transport* } \\
\quad(n=20)\end{array}$ & $\begin{array}{c}\text { ALS-pronounce* } \\
(n=20)\end{array}$ \\
\hline \multicolumn{3}{|l|}{ Time to CPR, $\min$} \\
\hline Witnessed, $<10$ & 12 & 12 \\
\hline $\begin{array}{l}\text { Unwitnessed, last } \\
\text { seen }<60\end{array}$ & 3 & 3 \\
\hline $\begin{array}{l}\text { Unwitnessed, last } \\
\text { seen } \geq 60\end{array}$ & 5 & 5 \\
\hline $\begin{array}{l}\text { Presence of a DNR } \\
\text { order }\end{array}$ & 0 & 0 \\
\hline $\begin{array}{l}\text { Pre-existing terminal } \\
\text { condition }\end{array}$ & 0 & 0 \\
\hline $\begin{array}{l}\text { Initial field rhythm } \\
\text { (VF/asystole/PEA) }\end{array}$ & $4 / 11 / 5$ & $4 / 11 / 5$ \\
\hline $\begin{array}{l}\text { No response to initial } \\
\text { therapy }\end{array}$ & 20 & 20 \\
\hline
\end{tabular}


er amount of emergency physician time but required a longer period of paramedic involvement.

Several investigators have studied prehospital care costs, but none have addressed this topic. Bonnin and coworkers estimated that transporting patients to the hospital for "continued but futile" resuscitation would cost US\$2000 to $\$ 3000$ per patient. Extrapolated nationally, this could increase total US health care expenditures by $\$ 500$ million. However, Bonnin and coworkers' cost estimate for transporting a patient to the hospital for physician pronouncement is substantially higher than the cost estimates determined in this study. This, in part, reflects an underestimation of ED physician costs in our study, since time spent with grieving family members was inconsistently recorded in ED charts. In fact, we identified only 1 case among the 20 pronounced in the ED for which counselling or family interview was documented and billed accordingly. Moreover, institutional costs were unavailable and not included in our analysis. Despite these factors, which would underestimate the cost of ED pronouncement, ED pronouncement was found to be more expensive.

Within our analysis, the clinical outcomes of each approach were assumed to be equal. However, while the same group of base hospital physicians made the decision to terminate resuscitation, either by patch or directly in the ED, field pronouncement may be perceived as a denial of the potential benefit of transport to an ED. In addition, out-ofhospital pronouncement may not meet the expectations of family members at the scene, and may deny them access to whatever support services are available in EDs.

There is little information regarding the preferences of surviving family members for field vs. ED pronouncement. One study showed that, when resuscitation was terminated

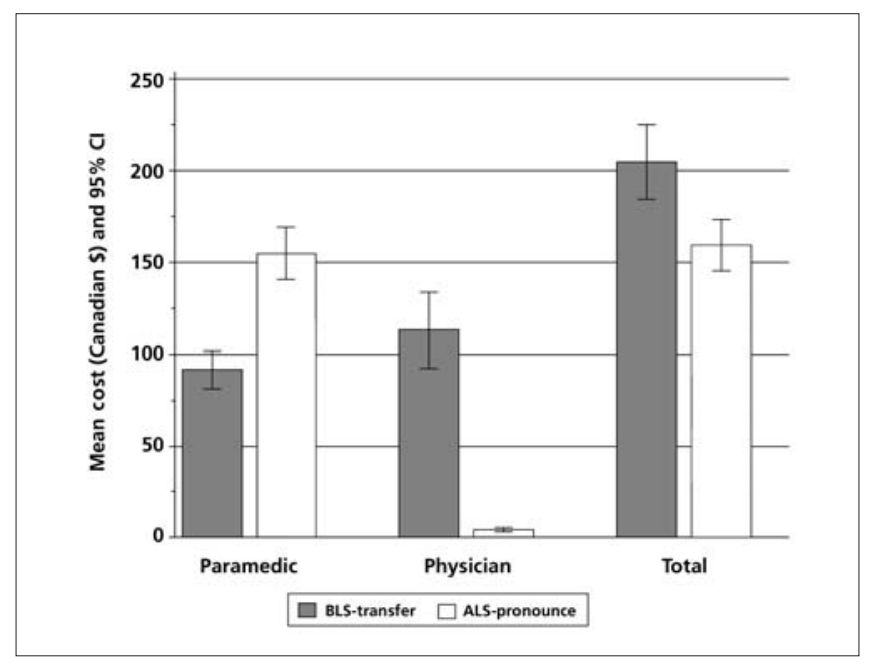

Fig. 2. Provider costs for field (ALS-pronounce) vs. ED (BLStransfer) pronouncement in the field, $96 \%$ of family members expressed satisfaction with the decision, and when resuscitation was terminated in the ED, $82 \%$ expressed satisfaction with the decision to transport (though $76 \%$ in the latter group felt field termination would have been acceptable). ${ }^{30}$ In another study of 31 family members of patients who had died out-of-hospital, none believed that their loved ones should have been transported to a hospital. ${ }^{31}$ This body of literature suggests that paramedics with base hospital support may be able to meet the needs of a patient's family members when performing field pronouncement.

In addition to higher costs, we found that more physician time was necessary to pronounce patients dead in the ED than in the field. The data presented may underestimate the true physician time requirement to complete all aspects of ED pronouncement. Our study did not include a measurement or estimate of the case-specific time required of the physician to contact and inform family members, support the bereaved, contact the coroner, complete medicolegal documentation and debrief ED staff. This time interval is important in that it represents a diversion from the care of other potentially viable ED patients. The 27.5-min paramedic time difference for ALS- vs. BLS-attended patients can be attributed to the ALS functions of supporting the survivors and completing the associated documentation. Of note, we previously determined that our ALS paramedics spend an average of 11.8 minutes talking to survivors and 28.4 minutes documenting the cases. ${ }^{32}$

\section{Limitations}

This study had several limitations. First, by including only cases with complete documentation, we may have introduced a selection bias. In addition, the need to match pa-

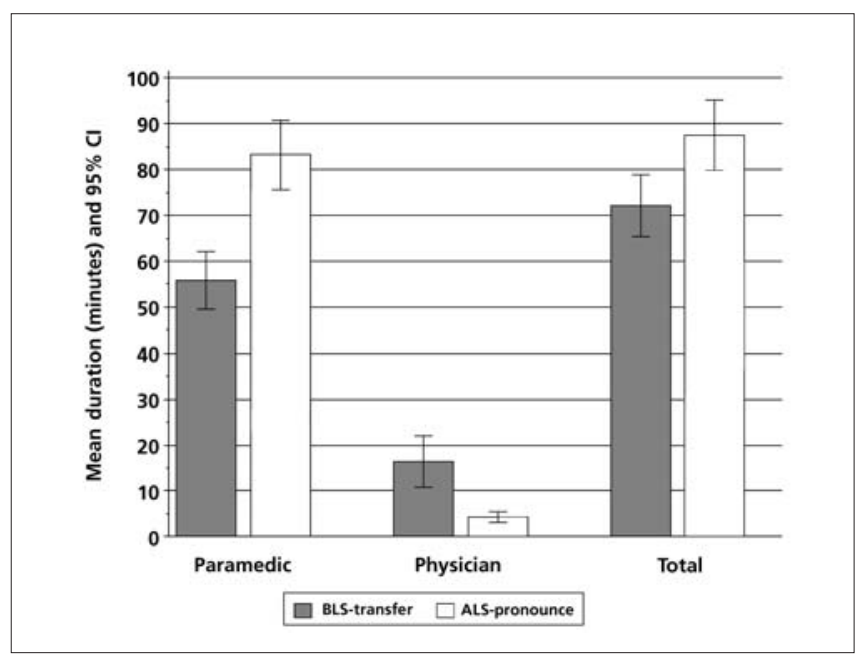

Fig. 3. Provider times for field (ALS-pronounce) vs. ED (BLStransfer) pronouncement 
tients on multiple predictor variables led to selective exclusion of patients who had extreme values for one or more matching parameters (e.g., very old or young patients were more difficult to match than patients in other age groups). As a consequence, excluded cases may have differed from the matched patients in the study.

Second, our economic analysis was restricted in scope. We estimated only direct medical costs and were unable to obtain some institutional costs. We did not consider non-medical, indirect (e.g., loss of income) or intangible (e.g., psychosocial) costs, some of which may have influenced the study conclusions. For example, with ALS field pronouncement there might have been an unmeasured survivor burden or psychological impact related to leaving the body at the scene. In this situation, the lack of immediate support from physicians, social workers or pastoral care representatives may also have generated unmeasured intangible costs. Paramedics have not been compared to other professionals with respect to their ability to provide support to survivors after out-ofhospital death. However, one study reported that $74 \%$ of survivors felt they had been informed in a supportive manner. In the same study, 58\% reported "good" adjustment within 11 to 15 months,,$^{31}$ suggesting that field pronouncement is not associated with untoward psychological sequelae. Some BLS-transport costs we failed to measure included those of diverting ED staff and resources away from other important patient care and the potential risks to paramedics and citizens of driving to the ED using lights and sirens..$^{17,20}$

Finally, external validity is a concern, and the generalizability of our data to other EMS systems may be limited, depending on local health delivery models, care costs, resource constraints, EMS resources and provider characteristics. ${ }^{27}$

\section{Conclusions}

Given our aging population and the shift toward communitybased care, we expect to see more out-of-hospital deaths in the future. This study suggests an economic advantage for field vs. ED pronouncement of selected cardiac arrest victims who are unlikely to survive resuscitation. With increasingly overburdened EDs and the planned expansion of Ontario prehospital care systems, field pronouncement will become more feasible and desirable. Future studies should focus on the acceptability of field pronouncement to survivors of cardiac arrest patients, paramedics and base hospital physicians.

Acknowledgements. Funding: Medical Research Council, Summer Student Scholarship, University of Toronto, Toronto, Ont. Manuscript assistance: Ms. Marian Vermeulen, Program Manager, Research Program, Division of Prehospital Care, Sunnybrook and Women's College Health Sciences Centre, Toronto.

\section{References}

1. Cummins R. Emergency medical services and sudden cardiac arrest: the "chain of survival" concept. Ann Rev Publ Health 1993;14:313-33.

2. Eisenberg MS, Pantridge JF, Cobb LA, Geddes JS. The revolution and evolution of prehospital cardiac care. Arch Intern Med 1996;156:1611-9.

3. Eisenberg MS, Cummins RO, Damon S, Larsen MP, Hearne TR. Survival rates from out-of-hospital cardiac arrest: recommendations for uniform definitions and data to report. Ann Emerg Med 1990;19:1249-59.

4. Brison RJ, Davidson JR, Dreyer JF. Cardiac arrest in Ontario: circumstances, community response, role of prehospital defibrillation and predictors of survival. CMAJ 1992;147:191-9.

5. Stiell IG, Wells GA, Field BJ. Improved out-of-hospital cardiac arrest survival through the inexpensive optimization of an existing defibrillation program: OPALS study phase II. Ontario Prehospital Advanced Life Support. JAMA 1999;281:1175-81.

6. Bonnin MJ, Swor RA. Outcomes in unsuccessful field resuscitation attempts. Ann Emerg Med 1989;18:507-12.

7. Bonnin MJ, Pepe PE, Kimball KT, Clark PS Jr. Distinct criteria for termination of resuscitation in the out-of-hospital setting. JAMA 1993; 270:1457-62.

8. Dull S, Cummins R, Graves J, Larson M. The futility of prehospital resuscitation of "end-of-life" cardiac arrests [abstract]. Ann Emerg Med 1990;19:467.

9. Eisenberg M, Bergner L, Hallstrom A. Paramedic programs and out-of-hospital cardiac arrest: factors associated with successful resuscitation. Am J Public Health 1979;69:30-8.

10. Gray WA, Capone RJ, Most AS. Unsuccessful emergency medical resuscitation: Are continued efforts in the emergency department justified? N Engl J Med 1991;325:1393-8.

11. Kellermann AL. Criteria for dead-on-arrivals, prehospital termination of CPR, and do-not-resuscitate orders. Ann Emerg Med 1993;22:47-51.

12. Markovchick V, Cantrill S, Pons P. Identification of these nontraumatic cardiac arrest patients for whom ED resuscitive effect are futile. Ann Emerg Med 1990;19:460.

13. Marsden AK, Ng GA, Dalziel K, Cobbe SM. When is it futile for ambulance personnel to initiate cardiopulmonary resuscitation? BMJ 1995;311:49-51.

14. Pepe P, Brown C, Bonnin M. Prospective validation of criteria for on-scene termination of resuscitation efforts after out-of-hospital cardiac arrest. Ann Emerg Med 1993;22:884-5.

15. Roth R, Stewart RD, Rogers K, Cannon GM. Out-of-hospital cardiac arrest: factors associated with survival. Ann Emerg Med 1984;13:237-43.

16. Kellermann AL, Hackman BB. Terminating unsuccessful advanced cardiac life support in the field [editorial]. Am J Emerg Med 1987;5:548-9.

17. Frank M. Should we terminate futile resuscitations in the field? Can we afford not to? [editorial]. Ann Emerg Med 1989;18: 594-6.

18. Gray WA. Prehospital resuscitation. The good, the bad, and the futile [editorial]. JAMA 1993;270:1471-2.

19. Jecker NS, Schneiderman LJ. An ethical analysis of the use of "futility" in the 1992 American Heart Association Guidelines for cardiopulmonary resuscitation and emergency cardiac care. Arch Intern Med 1993;153:2195-8. 
20. Auerbach PS, Morris JA Jr, Phillips JB Jr, Redlinger SR, Vaughn WK. An analysis of ambulance accidents in Tennessee. JAMA 1987;258:1487-90.

21. Hick JL, Mahoney BD, Lappe M. Factors influencing hospital transport of patients in continuing cardiac arrest. Ann Emerg Med 1998;32:19-25.

22. Eisenberg M. Improving out-of-hospital resuscitation. Lancet 1994;344:561-2.

23. Jakobsson J, Nyquist O, Rehnqvist N, Norberg KA. Cost of a saved life following out-of-hospital cardiac arrest resuscitated by specially trained ambulance personnel. Acta Anaesthesiol Scand 1987;31:426-9.

24. How to read clinical journals: VII. To understand an economic evaluation (part A). CMAJ 1984;130:1428-34.

25. Council on Health Strategy. Health Manual of Operational Directives and Guidelines. Ontario Ministry of Health, Emergency Health Services; 1997.

26. Stiell IG, Wells GA, Spaite DW, Lyver MB, Munkley DP, Field BJ, et al. The Ontario Prehospital Advanced Life Support (OPALS) Study: rationale and methodology for cardiac arrest patients. Ann Emerg Med 1998;32:180-90.
27. Nichol G, Laupacis A, Stiell IG, O'Rourke K, Anis A, Bolley H, et al. Cost-effectiveness analysis of potential improvements to emergency medical services for victims of out-of-hospital cardiac arrest. Ann Emerg Med 1996;27:711-20.

28. Eisenberg JM. Clinical economics. A guide to the economic analysis of clinical practices. JAMA 1989;262:2879-86.

29. Borenstein M, Rothstein H, Cohen J. Power and Precision. Teaneck (NJ): Biostat; 1997.

30. Delbridge TR, Fosnocht DE, Garrison HG, Auble TE. Field termination of unsuccessful out-of-hospital cardiac arrest resuscitation: acceptance by family members. Ann Emerg Med 1996; 27:649-54.

31. Schmidt TA, Harrahill MA. Family response to out-of-hospital death. Acad Emerg Med 1995;2:513-8.

32. Redelmeier DA, Morrison LJ. Record keeping and compassionate care [letter]. Lancet 1998;352:2025.

Correspondence to: Dr. Laurie Morrison, Sunnybrook and Women's College Health Sciences Centre, Rm. BG20, 2075 Bayview Ave., Toronto ON M4N 3M5; 416 480-6056, fax 416 480-6797; phc.research@utoronto.ca

\section{The best place for your landmark article}

$\mathrm{N}$ ew journals face a critical catch-22. The National Library of Medicine (MEDLINE) will not index a new journal until it is publishing high quality scientific material, but authors would rather not submit high quality scientific articles to a new journal until it is indexed. Consequently, one of the big challenges for any new journal is to attract good authors and high quality articles.

Authors want their work to reach the largest possible audience, and want their article catalogued in a searchable electronic database so future readers and researchers can reference it easily. While CJEM is not yet an indexed journal, we have addressed both these issues. In terms of visibility, CJEM is distributed to all Canadian emergency physicians and residency programs, giving it the largest Canadian readership of any EM journal. In addition, CJEM is distributed to over 150 US residency programs and to Canadian expatriates and "prominent" emergency physicians in Europe, Asia, Africa, Australia and the Middle East. Current CJEM distribution is 7,200 copies per issue, which compares favourably to other EM journals. Only Annals of Emergency Medicine has a substantially larger readership base and, of course, it does not come with an attractive teal cover or any kind of decent humour section.

To ensure that our articles reach an international audience, CJEM is the only EM journal freely available in full text format on the World Wide Web. This increases North American exposure and international penetration. While the exact level of the increase is unclear, some marketing experts suggest that a journal published on the Web will reach up to 10 times as many readers as the corresponding hard-copy journal. We therefore believe that articles published in CJEM will be read by more people than articles published in any other EM journal.

In addition, complimentary CJEM issues go to Drs. Jerry Hoffman and Rick Bukata, so that our articles can be reviewed on Emergency Medical Abstracts (EMA) tapes and enter the EMA database - perhaps the most useful article database for emergency physicians.

After our first full year of publication we became eligible to apply for National Library of Medicine indexing. While this is not a "sure thing," we have been told that, based on the quality of the journal so far, CJEM is likely to be accepted. If so, then articles published prior to indexing will be retrospectively added to the MEDLINE database. In the interim, our articles are available to anyone who performs an Internet search.

For now, the New England Journal of Medicine remains the more prestigious of the 2 journals, but those days are numbered. If you have a landmark article and no connections in Boston, remember that CJEM offers peer-review publication, a large reading audience, and - maybe - a free tee-shirt (we're still thinking about this one). 